\title{
The Effects of Different Pre-operative Information Timings on Patients' Anxiety Level and Pain Perception
}

\author{
Nurcan Tezci ${ }^{1}$, Burcu Karaduman ${ }^{2}$ \\ ${ }^{1}$ Kucukcekmece Oral and Dental Health Hospital, Istanbul, Turkey. \\ ${ }^{2}$ Biruni University, Faculty of Dentistry, Department of Periodontology, Istanbul, Turkey. \\ Correspondence Author: Burcu Karaduman \\ E-mail: bkaraduman@biruni.edu.tr \\ Received: $28.09 .2020 \quad$ Accepted: 15.09 .2021
}

\begin{abstract}
Objective: The purpose of this study was to investigate the impact of different timings of pre-operative information on patients' anxiety level and pain perception after open flap debridement.

Methods: 45 individuals with chronic periodontitis were equally allocated to the following groups: Group 1: Informed 7 days before surgery; Group 2: Informed 1 month before the surgery and Group 3: Informed by other dentists. All patients received open flap debridement. The anxiety level before surgery was evaluated by State-Trait Anxiety Inventory (STAI) and the pain perception by Visual Analogue Scale (VAS) on the days 1,3 , and 7 after surgery.

Results: The state anxiety levels significantly increased immediately before surgery in all groups $(P<0.05)$. No statistically significant difference was found in terms of STAI and VAS between the groups $(P>0.05)$.

VAS 1st and 3rd day values were significantly correlated with STAI-Trait values ( $r=0.311, P=0.038$ and $r=0.422, P=0.004$, respectively).

Conclusion: Pre-operative information provided by dentists at different times has no effect on post-operative pain and anxiety of the patients. Post-operative pain is associated with pre-operative anxiety. Determining the anxiety levels of patients before the operation acts an important part in the success of periodontal surgical treatments and pain management.

Keywords: Anxiety, Chronic Periodontitis, Postoperative Pain, Pain Assessment, Surgical Flap.
\end{abstract}

\section{INTRODUCTION}

Most of the dental treatments cause a certain level of anxiety affecting the course of the treatment in a negative way in patients. Bad experiences or complicated treatments in the past may affect the psychology of the patients, and in some cases, this occurs subconsciously resulting in fears called dental phobia (1). The fear and anxiety resulting from the previous experiences are difficult to overcome and can cause them to be stressed and feel tense during the treatment. In parallel with this, patients who are more stressed in their daily lives have higher levels of anxiety during the treatment. Moreover, periodontal disease can become more severe with increased stress levels, which is a risk factor, and periodontal destruction can progress gradually. Increased anxiety may cause the dentist to become more nervous during the treatment and may decrease the success of the procedure. Therefore, reducing stress levels in patients is one of the important impacts that may increase the success rate in all dental treatments $(2,3)$.

The effect of anxiety level on pain perception has been shown previously (4). Pain levels have been shown to be higher in patients with high levels of anxiety, excitement and fear $(5,6)$. Among the patients with high anxiety levels, those with low pain thresholds have also higher pain expectations after stressful dental treatments (4). When patients experience excessive pain after the surgery, they tend to disrupt oral care, ending in complications of wound healing with the increase in post-operative analgesic use due to anxiety (5). Patients who undergo emergency surgery needed to use more post-operative analgesics due to the lack of preoperative information and psychological preparation (7). Therefore, minimizing stress level may well be beneficial in 
terms of post-treatment patient comfort and post-operative complications for the success of periodontal treatments.

Patients who require surgical periodontal treatment usually obtain information about the necessity of surgery from dentists, oral medicine specialists or periodontists. In particular, the patients who are advised to see a periodontist by another dentist with the knowledge that they should have periodontal surgery can investigate this operation from different sources until the surgery. Thus, some doubts arise in their minds and anxiety levels may increase. On the other hand, it may be beneficial to inform patients about the procedure in advance and prepare them for the treatment. Information about dental procedures is usually given to the patients in detail immediately before the procedure. However, the stress level of the patient is at the maximum level in this period. Therefore, it may be recommended to inform the patients in detail in the previous sessions, not immediately before the procedure, in order to reduce their concerns (8).

VAS has been used previously in many studies to assess pain after periodontal surgery (9-12). The State-Trait Anxiety Inventory (STAI) (13) was used in this present study to measure state anxiety and trait anxiety. The validity and reliability of the Turkish version of STAI were confirmed by Le Compte and Öner $(14,15)$. The inventory has two separate scales of 20 items each which are rated on a 4-point Likert-type scale. The first questionnaire, STAI-State (STAI-S), measures the level of state anxiety and determines how an individual feels at a given moment and under certain conditions. The second questionnaire, STAI-Trait (STAI-T) determines how patients feel about their general life, regardless of the circumstances and conditions in which they are concerned, in order to measure the trait anxiety level.

To the best of our knowledge, there is no study conducted on the effect of optimum timing of pre-operative information for periodontal surgical procedures in the literature. The purpose of this study was to investigate the impact of different timings of pre-operative information on patients' anxiety levels and pain perception. In our study which was performed on patients who had not undergone periodontal surgery before, we also aimed to analyze the correlation between anxiety and post-operative pain scores after periodontal flap surgery. The tested hypothesis was that timing of pre-operative information would affect patients' anxiety levels and pain perception.

\section{MATERIALS AND METHODS}

\subsection{Patient Selection}

The study protocol was approved by the Ethical Committee of Istanbul Aydın University, Faculty of Dentistry (Approval No: 480.2/011) and was carried out in accordance with the Helsinki protocols and the ethical requirements (16). After explaining the nature, risks, benefits, and procedures of research, informed written consent was obtained from all participants. The enrollment period was from March 2015 to December 2016.

The study was conducted on a total of 45 participants diagnosed clinically and radiographically as chronic periodontitis (CP) according to the International Classification of Periodontal Diseases and Conditions in 1999 (17). Patients requiring open flap debridement surgery in at least one quadrant with at least three teeth after non-surgical periodontal therapy were seen eligible to participate.

\subsection{Sample Size Calculation}

The sample size was calculated according to a previous study employing the same method (18). Power analysis calculations showed that each group requires at least 15 patients, with a confidence interval of $95 \%(\alpha=0.05)$.

\subsection{Inclusion Criteria}

1. Age $\geq 18$ years,

2. Diagnosis with chronic periodontitis requiring open flap debridement surgery,

3. No contraindication for periodontal surgery,

4. Not receiving periodontal treatment in the past 6 months from the date of enrollment,

5. Presence of at least 20 natural teeth.

\subsection{Exclusion Criteria}

1. Any evidence of severe or uncontrolled systemic diseases that may affect the outcome of periodontal treatment,

2. Pregnancy or lactation,

3. Taking any medication that interferes with the health of the periodontal tissues or their healing,

4. Psychiatric disorders and the use of psychotropic agents,

5. Taking anti-inflammatory drugs or systemic antibiotics in the past 6 months from the date of enrollment,

6. Alcohol or drug addiction,

7. History of aggressive periodontitis,

8. Previous history of periodontal or dental surgery,

9. Periodontal regenerative procedures.

\subsection{Study Design and Clinical Procedures}

The demographic data of patients, including gender, age, and smoking status were recorded. The panoramic radiographs were taken, and periodontal clinical parameters were recorded as a part of routine diagnosis. All patients received initial periodontal therapy (IPT). Open flap debridement was planned for residual pockets with probing pocket depths of 5-8 $\mathrm{mm}$ and clinical attachment loss of 3-4 mm exhibiting clinical signs of inflammation (Bleeding on Probing (BoP) 
and/or suppuration) following IPT. If the patient could not maintain an adequate standard of plaque control (The average individual scores for Plaque Index (19) and Gingival Index (20) were less than 1), no surgical treatment was scheduled. The patients were allocated to one of the following three groups:

Group 1: Informed 7 days prior to periodontal surgery $(n=$ 15).

Group 2: Informed 1 month prior to periodontal surgery (n $=15$ ).

Group 3: Regardless of information timing, informed by other dentists before referred to the Periodontology clinic $(n=15)$.

The patients in Group 1 and 2 were randomly assigned to each group by tossing of coin by an independent researcher who did not collect the data or perform the procedures. Individuals were given structured and standardized information about the operations at different times and their anxiety levels were compared. The potential association between timing of information, patients' demographic data and anxiety levels was also investigated.

\subsection{Periodontal Clinical Parameters}

The following clinical parameters were recorded in a sequential order at baseline and 4 weeks after IPT by blinded experienced periodontist (N.T.) who did not perform the surgical procedures: Plaque Index (19) (PI), Gingival Index (20) $(\mathrm{GI})$, probing pocket depth (PPD), BoP (21), gingival recession (GR) and clinical attachment level (CAL). The periodontal clinical parameters were used only for the diagnosis, and thus, no statistical evaluation on these parameters was performed.

\subsection{Initial Periodontal Therapy}

After completing the baseline monitoring, the participants received IPT including oral hygiene instructions, full mouth scaling and root planning under local anesthesia and occlusal therapy if necessary. Throughout the research process, patients were provided proper oral hygiene instructions and maintained self-performed oral hygiene. Scaling and root planning were performed once a week for 2 weeks by a blinded experienced periodontist (B.K.). IPT did not include any medications such as non-steroidal anti-inflammatory drugs or antibiotics.

\subsection{Surgical Procedure}

The surgical procedures were performed under local anesthesia by an experienced periodontist (B.K.) who also performed IPT. Following the intracrevicular incision, a mucoperiosteal periodontal flap was elevated. Only when necessary, vertical releasing incisions were performed to obtain a better access or closure of the surgical site. Periodontal defects were carefully debrided and the defects and the adjacent mucoperiosteal flaps were rinsed thoroughly with sterile saline. The root surfaces were thoroughly scaled and planned. The flaps were repositioned and primarily sutured.

\subsection{Post-operative Care}

The surgical procedures were performed under local anesthesia by an experienced periodontist (B.K.) who also performed IPT. Verbal and written post-operative instructions were given to all patients. Analgesics ( $2 \times 275 \mathrm{mg}$ non-steroidal anti-inflammatory drug i.e. NSAID/day) were prescribed when needed. The number of analgesics taken was recorded for 7 days. In addition, all patients were instructed to rinse with a $0.2 \%$ chlorhexidine gluconate solution for 60 seconds twice daily for 1 week after surgery for post-operative plaque control. The patients were advised not to smoke during the healing period. The sutures were removed 1 week after the surgery.

\subsection{Pain Evaluation}

The pain levels of the patients were recorded at postoperative days 1,3 , and 7 using a visual analogue scale (VAS) (22). The VAS used in this study consisted of a horizontal 10 cm line with no other sign, with descriptors 'no pain' at the beginning and 'worst pain ever' at the end. There were no other markings on the line. The patient was asked to place a mark on this line to indicate the level of intensity of pain. The distance from 'no pain' (0) to the point marked by the patient was measured and recorded in centimeters.

\subsection{State-Trait Anxiety Inventory (STAI)}

In answering the STAI-S, patients were asked to choose one of the following responses: 1) not at all, 2) somewhat, 3) moderately so, and 4) very much so; while answering the STAI-T, patients were asked to choose one of the following responses: 1) almost never, 2) sometimes, 3) often, and 4) almost always, respectively. The total score for each subscale varies between 20 and 80 . High levels of anxiety are associated with higher scores.

STAI-S and STAI-T questionnaires were applied respectively at the beginning of the study (t1). All patients completed the questionnaire by themselves. Unclear questions were explained by the researcher. The STAI-S questionnaire was repeated immediately after the patients were informed about the surgery ( $\mathrm{t} 2$ ) and immediately before the operation (t3). The patients in group 3 were previously referred to the periodontology clinic after receiving information about the surgery. Therefore, STAI-S was not applied immediately after the patients were informed about the surgery in this group.

\subsection{Statistical Analyses}

All statistical analyses in this study were performed using Number Cruncher Statistical System (NCSS 2007 Statistical Software, Utah, USA). Continuous variables are expressed as mean and standard deviation (SD) values. The Friedman 
test for repeated measures of multiple groups, the Kruskal Wallis test for comparisons between the groups, the Dunn's multiple comparison test for subgroup comparisons, the Wilcoxon test for two-way repeated measures of groups, the Mann-Whitney $U$ test for comparison of paired groups, the Chi-square test for comparison of the qualitative data, and the Pearson Correlation test to determine the strength of association between the variables were used. A $P$ value less than 0.05 was considered statistically significant.

\section{RESULTS}

No postoperative complication was observed in any participants. A total of 45 patients (21 males, 24 females) with a mean age of $44.2 \pm 12.16$ participated in the study. In any demographic data, there was no statistically significant difference between the groups $(P>0.05)$ (Table 1). The differences in the amount of analgesic consumed and the amount of smoking were not statistically significant between the groups $(P>0.05)$ (Table 1$)$.

Table 1. The demographic data of the participants in the groups.

\begin{tabular}{|c|c|c|c|c|c|c|c|c|}
\hline \multirow{2}{*}{$\begin{array}{l}\text { Age } \\
\text { (mean } \pm S D)\end{array}$} & & \multicolumn{2}{|c|}{$\begin{array}{c}\text { Group } 1 \\
(n=15)\end{array}$} & \multicolumn{2}{|c|}{$\begin{array}{c}\text { Group } 2 \\
(n=15)\end{array}$} & \multicolumn{2}{|c|}{$\begin{array}{c}\text { Group } 3 \\
(n=15)\end{array}$} & $P^{*}$ \\
\hline & & \multicolumn{2}{|c|}{$47.47 \pm 12.88$} & \multicolumn{2}{|c|}{$43.13 \pm 10.88$} & \multicolumn{2}{|c|}{$44.2 \pm 12.16$} & 0.592 \\
\hline \multirow{2}{*}{$\begin{array}{l}\text { Gender } \\
\text { (n, \%) }\end{array}$} & Male & 6 & $40.00 \%$ & 7 & $46.67 \%$ & 8 & $53.33 \%$ & \multirow{2}{*}{0.765} \\
\hline & Female & 9 & $60.00 \%$ & 8 & $53.33 \%$ & 7 & $46.67 \%$ & \\
\hline \multirow{3}{*}{$\begin{array}{l}\text { Smoking } \\
\text { status } \\
(n, \%)\end{array}$} & Smoker & 7 & $46.67 \%$ & 9 & $60.00 \%$ & 9 & $60.00 \%$ & \multirow{3}{*}{0.677} \\
\hline & $\begin{array}{l}\text { Never } \\
\text { smoker }\end{array}$ & 6 & $40.00 \%$ & 3 & $20.00 \%$ & 1 & $6.67 \%$ & \\
\hline & $\begin{array}{l}\text { Former } \\
\text { smoker }\end{array}$ & 2 & $13.33 \%$ & 3 & $20.00 \%$ & 5 & $33.33 \%$ & \\
\hline \multicolumn{2}{|l|}{$\begin{array}{l}\text { The } \\
\text { number of } \\
\text { cigarettes } \\
\text { (mean } \pm S D \text { ) }\end{array}$} & \multicolumn{2}{|c|}{$13.40 \pm 7.09$} & \multicolumn{2}{|c|}{$7.33 \pm 2.52$} & \multicolumn{2}{|c|}{$8.6 \pm 4.72$} & 0.399 \\
\hline \multirow{2}{*}{$\begin{array}{l}\text { Use of } \\
\text { analgesics } \\
(n, \%)\end{array}$} & + & 5 & $33.33 \%$ & 4 & $26.67 \%$ & 3 & $20.00 \%$ & \multirow{2}{*}{0.711} \\
\hline & - & 10 & $66.67 \%$ & 11 & $73.33 \%$ & 12 & $80.00 \%$ & \\
\hline $\begin{array}{l}\text { The } \\
\text { number of } \\
\text { analgesics } \\
\text { used } \\
\text { (mean士SD) }\end{array}$ & & \multicolumn{2}{|c|}{$1.9 \pm 1.2$} & \multicolumn{2}{|c|}{$3.27 \pm 1.95$} & \multicolumn{2}{|c|}{$3.67 \pm 2.31$} & 0.101 \\
\hline
\end{tabular}

SD: Standard Deviation, $n$ : Number. ${ }^{*} P<0.05$ was considered statistically significant (The Kruskal Wallis test and the Chi-square test).

\section{STAI-S and STAI-T}

The anxiety levels of the groups at different times are shown in Table 2. Group 1 exhibited a statistically significant increase in STAI-S between t1, t2 and t3 times $(P=0.006)$. STAI-S at t3 time was found to be significantly higher than t1 and t2 $(P=0.006$ and $P=0.021$, respectively), although there was no statistically significant difference between t1 and t2 times $(P=0.176)$.

In group 2, there was a statistically significant increase in STAI-S between $\mathrm{t} 1, \mathrm{t} 2$ and $\mathrm{t} 3$ times $(P=0.003)$. At the time $\mathrm{t} 1$, STAI-S was significantly lower than $\mathrm{t} 2$ and $\mathrm{t} 3(P=0.036$ and $P=0.003$, respectively) and a statistically significant difference was also found between $\mathrm{t} 2$ and $\mathrm{t} 3(P=0.202)$.

In Group 3, STAI-S was found to be statistically significantly higher at $\mathrm{t} 3$ time than $\mathrm{t} 1(P=0.019)$.

The STAI-S of Group 3 was higher than Group 1 and Group 2 at $\mathrm{t} 1$, although this difference was not statistically significant $(P=0.052)$. There were no statistically significant differences between groups at any time point in STAI-S and at $\mathrm{t} 1$ in STAI-T $(P>0.05)$.

Table 2. STAI-S and STAI-T values of the study groups at different times.

\begin{tabular}{|l|l|l|l|l|}
\hline $\begin{array}{l}\text { STAI-S } \\
(\text { mean } \pm \text { SD) }\end{array}$ & $\begin{array}{l}\text { Group } \mathbf{1} \\
(\boldsymbol{n}=\mathbf{1 5})\end{array}$ & $\begin{array}{l}\text { Group 2 } \\
(\boldsymbol{n}=\mathbf{1 5})\end{array}$ & $\begin{array}{l}\text { Group 3 } \\
(\boldsymbol{n}=\mathbf{1 5})\end{array}$ & $\boldsymbol{p}^{*}$ \\
\hline $\boldsymbol{t} \mathbf{1}$ & $29.47 \pm 08.77$ & $29.47 \pm 7.09$ & $38.00 \pm 14.74$ & 0.052 \\
\hline $\boldsymbol{t} \mathbf{t 3}$ & $31.93 \pm 10.69$ & $33.93 \pm 8.61$ & NA & 0.577 \\
\hline $\boldsymbol{P}^{+}$ & $37.00 \pm 11.92$ & $36.47 \pm 8.37$ & $41.93 \pm 13.00$ & 0.351 \\
\hline $\begin{array}{l}\text { STAI-T } \\
\text { (mean } \pm S D)\end{array}$ & $\mathbf{0 . 0 0 6 ^ { + }}$ & $\mathbf{0 . 0 0 3 ^ { + }}$ & $\mathbf{0 . 0 1 9 ^ { + }}$ & \\
\hline
\end{tabular}

STAI: State-Trait Anxiety Inventory, STAI-S: STAI-State, STAI-T: STAI-Trait, SD: Standard Deviation, $n$ : Number, NA: Non-available, $t$ : Time. ${ }^{*} P<0.05$ was considered statistically significant (The Kruskal Wallis test and the Chisquare test). $+P<0.05$ was considered statistically significant (The Friedman test and the Wilcoxon test).

\section{VAS}

The pain perceptions of the groups at different times are shown in Table 3. There was a statistically significant decrease in VAS of Group 1 between days 1,3 , and $7(P=0.0001)$. The VAS of day 1 was found to be significantly higher than days 3 and $7(P=0.003)$, although there was no statistically significant difference between the VAS on day 3 and day $7(P=0.238)$.

There was a statistically significant decrease in VAS of Group 2 between days 1,3 and $7(P=0.0001)$. The VAS of day 1 was found to be significantly higher than days 3 and $7(P=0.0001)$. The VAS on day 1 was significantly higher than VAS on day 3 and day $7(P=0.0001)$, and the VAS on day 3 were significantly higher than VAS on day $7(P=0.015)$.

There was a statistically significant decrease in VAS of Group 3 between days 1,3 , and $7(P=0.0001)$. The mean VAS of day 1 was found to be statistically significantly higher than the mean of day 3 and 7 ( $P=0.001$ and $P=0.0001$, respectively), although there was no statistically significant difference between the VAS on day 3 and day $7(P=0.179)$.

There was no statistically significant difference between the groups at any time point $(P>0.05)$. VAS 1 st and 3rd day values were significantly correlated with STAI-T values $(r=0.311$, $P=0.038$ and $r=0.422, P=0.004$, respectively). 
Table 3. Pain perception of the groups at different times.

\begin{tabular}{lllll} 
VAS & $\begin{array}{l}\text { Group 1 } \\
(n=15)\end{array}$ & $\begin{array}{l}\text { Group 2 } \\
(n=15)\end{array}$ & $\begin{array}{l}\text { Group 3 } \\
(n=15)\end{array}$ & $\boldsymbol{P}^{*}$ \\
\hline $\begin{array}{l}\text { Day 1 } \\
\text { (mean } \pm S D)\end{array}$ & $1.500 \pm 1.603$ & $2.753 \pm 1.623$ & $2.647 \pm 2.403$ & 0.151 \\
\hline $\begin{array}{l}\text { Day 3 } \\
\text { (mean } \pm S D)\end{array}$ & $0.133 \pm 0.419$ & $0.867 \pm 1.175$ & $0.720 \pm 1.880$ & 0.275 \\
\hline $\begin{array}{l}\text { Day 7 } \\
\text { (mean } \pm S D)\end{array}$ & $0.000 \pm 0.000$ & $0.067 \pm 0.209$ & $0.040 \pm 0.155$ & 0.480 \\
\hline $\mathbf{P}^{+}$ & $\mathbf{0 . 0 0 0 1 ^ { + }}$ & $\mathbf{0 . 0 0 0 1 ^ { + }}$ & $\mathbf{0 . 0 0 0 1 ^ { + }}$ & \\
\hline
\end{tabular}

VAS: Visual Analogue Scale, SD: Standard Deviation, $n$ : Number. ${ }^{*} p<0.05$ was considered statistically significant (The Kruskal Wallis test and the Chisquare test). $+P<0.05$ was considered statistically significant (The Friedman test and the Wilcoxon test).

\section{DISCUSSION}

The main purpose of periodontal treatment is to stop or prevent periodontal infection by removing pathogenic periodontal microflora and trying to eliminate risk factors, but also to provide regeneration in periodontal supporting tissues (23). Surgical treatment techniques such as open flap debridement are frequently applied for this purpose, particularly in the management of severe periodontitis, especially with severe clinical attachment loss (11). In the treatment and long-term maintenance of patients with chronic periodontitis who require open flap debridement, stress and anxiety can affect the severity of the disease, the course of the treatment, and also the postoperative pain level $(2,3)$. Therefore, stress and anxiety levels should be minimized in surgical procedures with the aim of providing maximum periodontal recovery and minimum complications (2). Different and unknown therapies can cause a certain level of anxiety in patients, and the anxiety level of patients who receive information from other sources, such as other patients who receive treatment and the internet, may increase during the time until the operation (4). In our study, we sought an answer to the question of when the pre-operative information should be transmitted, which may affect the treatment process by affecting the stress and anxiety levels in periodontal flap operations. To the best of our knowledge, there is no article in the literature that investigates the effect of timing of pre-operative information on these parameters.

In our study, state anxiety levels significantly increased immediately before surgery in all groups, as expected. However, no statistically significant difference was found in terms of anxiety between different timings of pre-operative information. The levels of anxiety state at baseline were found to be higher in patients who were referred by another dentist with the knowledge of prospective surgery. However, the anxiety levels of patients in this group immediately before surgery were found to be similar to the other groups. Contrary to our findings, there are limited studies showing that individuals informed before the day of surgery have higher pre-operative anxiety (24). In the current study, no relationship between informing period and pain perception was found, although higher VAS values were seen in individuals informed 1 month prior to periodontal surgery. This finding can be attributed to the fact that the patients in this group had higher pain expectancy with the increase in anxiety and fear levels related to surgery for 1 month period until the time of operation. In a recent systematic review, it was revealed that different timings of pre-operative information had no effect on pre-operative anxiety or postoperative pain, in line with the findings of our study (25). However, our study is the first report describing the effect of informing period on post-operative pain and anxiety for periodontal surgical procedures. Since there are no previous reports, we could not compare our findings.

Post-operative pain is an acute pathological pain that starts with surgery, gradually decreases during the recovery phase and ends with tissue healing. The post-operative pain levels of the patients were evaluated by a visual analog scale in the present study, since it's a simple, sensitive, and reliable method that takes a short time $(26,27)$. In addition, it has been reported that the VAS scale which is $10 \mathrm{~cm}$ in length is the most appropriate scale for the measurement of dental pain compared to the other dimensions (28). In our study, post-operative pain perception was observed to decrease over time in all groups. The VAS scores were close to zero in all groups at the end of the study. Consistent with previous studies, this study demonstrated that a majority of patients exhibited mild pain perception during the first week of recovery following open flap debridement and pain was generally well tolerated (29-31). However, in the study of Canakci et al. (23), which was inconsistent with the findings of our study, a higher pain perception was reported in patients receiving open flap debridement. The reason for the discrepancy between studies may be due to the inhomogeneity of variables that affect the perception of pain.

The findings of this study have to be seen in the light of some limitations. In addition to the factors related to the patient (gender, socio-economic status, age, and education level), many factors such as the location and size of the surgical site, the type of incision, and the surgery duration affect the duration and severity of the post-surgical pain. However, anxiety, fear, and individual differences in pain perception are considered to be important determinants of post-operative pain. In our study, analyses of other factors affecting anxiety or pain were not conducted, and the relationship between state and trait anxiety and pain in the post-operative period was investigated. Furthermore, this study was initiated and conducted in groups with similar demographic data including age, gender, smoking status and socioeconomic status.

In the present study, pre-operative anxiety levels of the patients were also compared to their pain perception, and a significant correlation was observed between STAI-T and the 3rd and 7th-day VAS scores. Similar to our findings, it has been observed in many studies that higher anxiety levels before periodontal surgical procedures were positively correlated with postoperative pain level $(9,11,23)$. Trait anxiety level has been suggested as a predictor for pre - and post-operative pain (32). 
Pre-operative anxiety is associated with increased postoperative pain and thus, increased analgesic consumption during this period. In our study, the amount of analgesic used was not different between the groups. This finding seems to be related to the other findings of our study, which showed no difference between different timings of pre-operative information in terms of pre-operative anxiety and therefore post-operative pain perception.

\section{CONCLUSION}

Pre-operative information provided by dentists at different times has no effect on post-operative pain and anxiety of the patients. Post-operative pain is associated with preoperative anxiety. Determining the anxiety levels of patients before the operation acts an important part in the success of periodontal surgical treatments and pain management. Further studies including other factors influencing pain and anxiety and incorporating a greater number of participants are needed to confirm these results.

Conflicts of interest: The authors have declared that there are no conflicts of interest.

This original article was presented as a poster presentation at Europerio 9, Amsterdam, Netherlands.

Authors' contributions: NT and BK: Conception and design of the study, acquisition of data, analysis and interpretation of data. Drafting of manuscript: NT and BK. All authors revised the article critically for important intellectual content, and all authors approved the final version of the manuscript to be submitted.

\section{REFERENCES}

[1] Abrahamsson KH, Berggren U, Hallberg L, Carlsson SG. Dental phobic patients' view of dental anxiety and experiences in dental care: a qualitative study. Scand J Caring Sci. 2002 Jun;16(2):188-196.

[2] Kloostra PW, Eber RM, Inglehart MR. Anxiety, Stress, Depression, and Patients' Responses to Periodontal Treatment: Periodontists' Knowledge and Professional Behavior. J Periodontol. 2007 Jan;78(1):64-71.

[3] Doyle CJ, Bartold PM. How does stress influence periodontitis? J Int Acad Periodontol. 2012;14(2):42-49.

[4] Klages U, Ulusoy O, Kianifard S, Wehrbein H. Dental trait anxiety and pain sensitivity as predictors of expected and experienced pain in stressful dental procedures. Eur J Oral Sci. 2004 Dec;112(6):477-483.

[5] Ip HYV, Abrishami A, Peng PWH, Wong J, Chung F. Predictors of Postoperative Pain and Analgesic Consumption. Anesthesiology. 2009 Sep;111(3):657-677.

[6] Solowiej K, Mason V, Upton D. Review of the relationship between stress and wound healing: part 1 . J Wound Care. 2009 Sep;18(9):357-366.

[7] Dahmani S, Dupont H, Mantz J, Desmonts JM, Keita H. Predictive factors of early morphine requirements in the post-anaesthesia care unit (PACU). Br J Anaesth. 2001 Sep;87(3):385-389.
[8] Schwartz-Arad D, Bar-Tal Y, Eli I. Effect of stress on information processing in the dental implant surgery setting. Clin Oral Implants Res. 2007 Feb;18(1):9-12.

[9] Fardal $\varnothing$, McCulloch CA. Impact of Anxiety on Pain Perception Associated With Periodontal and Implant Surgery in a Private Practice. J Periodontol. 2012 Sep;83(9):1079-1085.

[10] Beaudette JR, Fritz PC, Sullivan PJ, Piccini A, Ward WE. Investigation of factors that influence pain experienced and the use of pain medication following periodontal surgery. J Clin Periodontol. 2018 May;45(5):578-585.

[11] Ahmadi M, Kiakojori A, Moudi S. Association of Anxiety with Pain Perception following Periodontal Flap Surgery. J Int Soc Prev Community Dent. 2018;8(1):28-33.

[12] Steffens JP, Santos FA, Pilatti GL. The Use of Etoricoxib and Celecoxib for Pain Prevention After Periodontal Surgery: A Double-Masked, Parallel-Group, Placebo-Controlled, Randomized Clinical Trial. J Periodontol. 2011 Sep;82(9):12381244.

[13] Spielberger CD. Manual for the State-Trait Anxiety Inventory (STAI Form Y). Consulting Psychologists Palo Alto. 1983.

[14] LeCompte A, Öner N. A study of the adaptation and standardization of state-trait anxiety inventory to Turkish. In IX. National Congress of Psychiatry and Neurological Sciences Studies; 1975. p. 457-462.

[15] Öner N, LeCompte A. Handbook of state-trait anxiety inventory. Boğaziçi University Edition; 1983.

[16] World Medical Association Inc. Declaration of Helsinki. Ethical principles for medical research involving human subjects. Journal of the Indian Medical Association 2009:403-405.

[17] Armitage GC. Development of a classification system. Ann Periodontol. 1999;4(1):1-6.

[18] Güner B, Pamuk AG, Yazıcı MK, Aypar Ü. informed Consent for an Anesthesia Study: How Does Timing Effect Parental Antiety Levels?. Turkiye Klin J Anest Reanim. 2011;9:90-101.

[19] Silness J, Löe H. Periodontal Disease In Pregnancy. II. Correlation Between Oral Hygiene And Periodontal Condition. Acta Odontol Scand. 1964;22:121-135.

[20] Löe H, Silness J. Periodontal Disease in Pregnancy I. Prevalence and Severity. Acta Odontol Scand. 1963 Jan;21(6):533-551.

[21] Ainamo J, Bay I. Problems and proposals for recording gingivitis and plaque. Int Dent J. 1975;25(4):229-235.

[22] Jensen MP, Karoly P, Braver S. The measurement of clinical pain intensity: a comparison of six methods. Pain. 1986;27(1):117126.

[23] Canakçi CF, Canakçi V. Pain experienced by patients undergoing different periodontal therapies. J Am Dent Assoc. 2007;138(12):1563-1573.

[24] Tait AR, Voepel-Lewis T, Siewert M, Malviya S. Factors that influence parents' decisions to consent to their child's participation in clinical anesthesia research. Anesth Analg. 1998;86(1):50-53.

[25] Hounsome J, Lee A, Greenhalgh J, Lewis SR, SchofieldRobinson OJ, Coldwell CH, Smith AF. A systematic review of information format and timing before scheduled adult surgery for peri-operative anxiety. Anaesthesia. 2017;72(10):12651272.

[26] Seymour RA. The use of pain scales in assessing the efficacy of analgesics in post-operative dental pain. Eur J Clin Pharmacol. 1982;23(5):441-444.

[27] Williamson A, Hoggart B. Pain: a review of three commonly used pain rating scales. J Clin Nurs. 2005;14(7):798-804. 
[28] Seymour RA, Simpson JM, Charlton EJ, Phillips ME. An evaluation of length and end-phrase of visual analogue scales in dental pain. Pain. 1985;21(2):177-185.

[29] Mei CC, Lee FY, Yeh HC. Assessment of pain perception following periodontal and implant surgeries. J Clin Periodontol. 2016;43(12):1151-1159.

[30] Tan WC, Krishnaswamy G, Ong MMA, Lang NP. Patient-reported outcome measures after routine periodontal and implant surgical procedures. J Clin Periodontol. 2014;41(6):618-624.
[31] Pradhan S, Shrestha R, Gorkhali RS. Pain Perception after Periodontal Therapies. J Nepal Soc Periodontol Oral Implantol. 2018;2(2):56-60.

[32] Hallegraeff JM, Kan R, van Trijffel E, Reneman MF. State anxiety improves prediction of pain and pain-related disability after 12 weeks in patients with acute low back pain: a cohort study. J Physiother. 2020;66(1):39-41.

How to cite this article: Tezci N, Karaduman B. The Effects of Different Pre-operative Information Timings on Patients' Anxiety Level and Pain Perception. Clin Exp Health Sci 2021; 11: 714-720. DOI: 10.33808/clinexphealthsci.801354 